\title{
History of blood transfusion before 1990 is associated with increased risk for cancer mortality independently of liver disease: a prospective long-term follow-up study
}

\author{
Yusuke Inoue $\cdot$ Yasuhiko Wada $\cdot$ Yutaka Motohashi • \\ Akio Koizumi
}

Received: 4 August 2009/Accepted: 18 November 2009/Published online: 17 December 2009

(C) The Japanese Society for Hygiene 2009

\begin{abstract}
Objectives The aim of this work is to investigate the association between transfusion history and cancer mortality in a prospective follow-up study.

Methods We conducted a prospective cohort study in four areas of Akita Prefecture, Japan, in 10,451 individuals (4,401 men and 6,050 women, aged 40-79 years) without history of cancer. The subjects were followed until 31 December 2003 and the number of deaths from cancer was recorded.

Results After mean follow-up of 12.76 years $(140,259$ person-years), 520 individuals (333 men and 187 women) died of cancer. History of blood transfusion before 1990 was mildly but significantly associated with overall cancer mortality (hazard ratio $=1.75,95 \%$ confidence interval: $1.32-2.18)$ and nonliver cancer mortality (HR $=1.68,95 \%$ CI: 1.25-2.26). This significant association remained unchanged after excluding deaths that occurred within 5 years of baseline for overall cancer mortality $(\mathrm{HR}=1.47,95 \% \mathrm{CI}: 1.04-2.09)$ and for nonliver cancer mortality (HR $=1.43,95 \%$ CI: $1.00-2.04)$. The significant association for nonliver cancer mortality was confirmed in subjects with no smoking history and/or alcohol
\end{abstract}

Y. Inoue · A. Koizumi ( $\square)$

Department of Health and Environmental Sciences,

Graduate School of Medicine, Kyoto University,

Yoshida-Konoe-cho, Sakyo-ku, Kyoto 606-8501, Japan

e-mail: koizumi@pbh.med.kyoto-u.ac.jp

Y. Wada

Department of Clinical Informatics, Kansai Rosai Hospital,

Hyogo, Japan

Y. Motohashi

Department of Public Health, Akita University

School of Medicine, Akita, Japan consumption (HR $=2.01$, 95\% CI: $1.35-3.00)$. Site-specific analysis showed a possible association between transfusion history and death from pancreatic cancer.

Conclusions History of blood transfusion before 1990 was found to be associated with increased risk for cancer mortality and was independent of liver diseases. The mechanism of the association between blood transfusion and cancer mortality warrants further research.

Keywords Cancer - Cohort studies .

Residence characteristics $\cdot$ Blood transfusion

\section{Introduction}

Although allogeneic blood transfusion is an established mode of therapy, it has several recognized risks. In this study, we aimed to test the hypothesis of a long-term biological influence of past transfusion on overall cancer mortality. Although many epidemiological studies have suggested that allogeneic blood transfusion is associated with increased risk for postoperative cancer recurrence [112], few studies have investigated the association between transfusion history and cancer mortality. One preliminary study has suggested that past transfusion might increase the risk for overall cancer mortality [13]. Therefore, further studies are needed to confirm this association, with adjustment for related lifestyle factors or past medical histories that might confound the association between cancer mortality and transfusion history.

We conducted a 14-year follow-up cohort study of middle-aged and elderly general population in Japan using self-report questionnaires on transfusion history and other factors that might confound analysis of the association between transfusion history and cancer mortality. 


\section{Materials and methods}

\section{Study cohort}

The cohort was established in four areas (areas A-D) in Akita Prefecture as part of the Japan Collaborative Cohort Study for evaluation of Cancer Risk (JACC study), which was ongoing for 14 years (from 1990 to 2003); the details of the study have been described in more detail elsewhere $[14,15]$. In brief, a total of 11,631 individuals $(4,865$ men and 6,766 women, aged 40-79 years) in the four areas participated in municipal health screening examinations between 1988 and 1991, which were conducted in accordance with Japan's law on health services for elderly people. All of the participants completed a self-administered questionnaire. The cohort study was set up in accordance with the ethical standards of the Helsinki Declaration, and the protocol and the data usage for this research was approved by the Research Ethics Committee of Kyoto University.

\section{Follow-up}

Date and cause of death were confirmed biannually, with the permission of the Director-General of the Prime Minister's Office (Ministry of Public Management, Home Affairs, Post, and Telecommunications). The date of moving away from the study area was also annually verified by the investigator in each area by reviewing the population register sheets of the cohort members. The time of follow-up for each subject was calculated from the day of enrollment in the study to the day of death from cancer or any other cause, the time of moving away from the study area or the end of 2003, whichever occurred first. By the end of 2003,14.2\% (944 men and 621 women) of the participants had died and 3.4\% (131 men and 241 women) were lost to follow-up because they had moved away from the study areas.

\section{Questionnaire}

At baseline, all participants completed self-administered questionnaires containing the following items: sex, age, birth date, medical history (transfusion, liver diseases, external injury that required hospitalization, and abdominal surgery), smoking status, alcohol consumption, and history of pregnancy. Medical histories and history of pregnancy were inquired about, using a yes/no question regarding whether the participant had a particular medical or pregnancy history. For example, for transfusion history, participants were asked, "Have you ever been treated with blood transfusion by the time of this survey?" For alcohol consumption, individuals chose their status from three categories: those who had never consumed alcohol, current drinkers or ex-drinkers. For smoking status, individuals chose from three categories: those who had never smoked, current smokers or ex-smokers. Those with unmarked or missing data in the questionnaire were not used in the analyses.

Data retrieval and analysis

We restricted the present analysis to include only those participants who provided information about their age, sex, and transfusion history, and who did not have history of cancer. Of the 11,631 participants, those with history of cancer $(n=638)$ and those with missing questionnaire data about their age, sex or transfusion history $(n=759)$ were not used in this analysis. A total of 1,180 individuals were excluded, and our final dataset comprised data from 10,451 individuals (4,401 men and 6,050 women, aged 4079 years). For deceased subjects, cause of death was recorded from death certificates and coded according to the International Classification of Diseases and Related Health Problems (ICD) tenth revision for deaths occurred after 1995 , or the ninth version for deaths that occurred between baseline and 1994; the latter were then recoded according to the tenth revision. Deaths due to malignant neoplasms were coded as 140-208 according to the ICD ninth revision (for deaths between baseline and 1994) and as C00-C97 according to the tenth revision (for deaths after 1995).

\section{Statistical analysis}

The Cox proportional-hazards model was used to calculate the age-adjusted and multivariate hazard ratio (HR) of history of blood transfusion for cancer mortality, along with the $95 \%$ confidence interval (CI). The risk of cancer mortality in patients with liver disease was also estimated. All calculations were performed using SAS version 8.2 software (SAS Inc., Cary, NC, USA). Differences at $P<0.05$ were considered statistically significant.

The multivariate HR of transfusion history for cancer mortality was estimated after adjusting for baseline age, sex, and typical risk factors of total cancer mortality (smoking status and alcohol consumption), and history of external injury, abdominal surgery, liver disease, and pregnancy, which were factors related to transfusion, or factors showing a significant association in age-adjusted univariate analysis.

\section{Results}

During average follow-up of 12.76 years $(140,259$ personyears), a total of 520 individuals (333 men and 187 women) 
died of cancer: 26 (15 men and 11 women) from liver cancer and 494 (318 men and 176 women) from nonliver cancer. Baseline characteristics are presented in Table 1. The prevalence of external injury $(41.0 \%)$, abdominal surgery $(73.7 \%)$, and liver disease (8.2\%) among subjects

Table 1 Demographic and clinical data of the study cohort

\begin{tabular}{|c|c|c|}
\hline & \multicolumn{2}{|c|}{ History of transfusion } \\
\hline & Yes $(n=972)$ & No $(n=9,479)$ \\
\hline \multicolumn{3}{|l|}{ Age } \\
\hline \multirow[t]{2}{*}{ Mean (SD), years } & $56.7(9.5)$ & $58.1(9.3)$ \\
\hline & $n(\%)$ & $n(\%)$ \\
\hline \multicolumn{3}{|l|}{ Area } \\
\hline A & $221(22.7)$ & $1,826(19.3)$ \\
\hline B & $247(25.4)$ & $1,834(19.3)$ \\
\hline $\mathrm{C}$ & $202(20.8)$ & $2,827(29.8)$ \\
\hline $\mathrm{D}$ & $302(31.1)$ & 2,992 (31.6) \\
\hline \multicolumn{3}{|l|}{ Number } \\
\hline Men & $352(36.2)$ & 4,049 (42.7) \\
\hline Women & $620(63.8)$ & $5,430(57.3)$ \\
\hline \multicolumn{3}{|l|}{ Smoking status } \\
\hline Never & $555(57.1)$ & $5,433(57.3)$ \\
\hline Smoker & $183(18.8)$ & $2,086(22.0)$ \\
\hline Ex-smoker & $103(10.6)$ & $726(7.7)$ \\
\hline Unknown & $131(13.5)$ & $1,234(13.0)$ \\
\hline \multicolumn{3}{|l|}{ Alcohol intake } \\
\hline Never & $433(44.5)$ & $4,246(44.8)$ \\
\hline Drinker & $396(40.7)$ & $4,278(45.1)$ \\
\hline Ex-drinker & $64(6.6)$ & $287(3.0)$ \\
\hline Unknown & $79(8.1)$ & $667(7.0)$ \\
\hline \multicolumn{3}{|c|}{ History of external injury } \\
\hline Yes & $399(41.0)$ & $1,673(17.7)$ \\
\hline No & $495(50.9)$ & 7,497 (79.1) \\
\hline Unknown & $78(8.0)$ & $308(3.2)$ \\
\hline \multicolumn{3}{|c|}{ History of abdominal surgery } \\
\hline Yes & $716(73.7)$ & $2,805(29.6)$ \\
\hline No & 229 (23.6) & $6,588(69.5)$ \\
\hline Unknown & $27(2.8)$ & $85(0.9)$ \\
\hline \multicolumn{3}{|c|}{ History of liver disease } \\
\hline Yes & $80(8.2)$ & $272(2.9)$ \\
\hline No & $821(84.5)$ & 8,777 (92.6) \\
\hline Unknown & $71(7.3)$ & $429(4.5)$ \\
\hline \multicolumn{3}{|c|}{ History of pregnancy ${ }^{a}$} \\
\hline Yes & $565(98.8)$ & $5,055(99.3)$ \\
\hline No & $7(1.2)$ & $37(0.7)$ \\
\hline
\end{tabular}

People with history of cancer before participation in the cohort were excluded from this analysis

$S D$ standard derivation

${ }^{\text {a }}$ Females only with history of blood transfusion was more than twice that of those without history of transfusion $(17.6 \%, 29.6 \%$, and $2.9 \%$, respectively) ( $P<0.001, \chi^{2}$ test). On the other hand, there was no significant difference in smoking status or alcohol intake between those with and those without history of blood transfusion.

Table 2 shows the age-adjusted HRs for cancer mortality for the sex-specific and sex-stratified analyses. Generally, history of blood transfusion was significantly associated with increased risk of cancer death, regardless of whether death was associated with liver cancer or nonliver cancer. Smoking status was also significantly associated with increased risk of cancer death. Current smoking and ex-smoking statuses were, respectively, associated with cancer mortality, for overall cancer and nonliver cancer. History of liver disease was significantly associated with increased risk for liver cancer mortality, although this association was not confirmed for mortality due to other cancers. In women, ex-drinking habit and history of external injury were also significantly associated with increased risk of cancer mortality. History of abdominal surgery and pregnancy were not significantly associated with cancer mortality.

On multivariate analysis, the significant association between cancer mortality and history of transfusion remained unchanged (Table 3). We also tested this association after excluding deaths in the first 5 years (totally 511 cases were excluded, including 120 cancer deaths), because such deaths might have resulted from unidentified factors that engendered a spurious association between transfusion and cancer mortality risk. Even after excluding deaths in the first 5 years, the significant association remained unchanged; the HR $(95 \%$ CI) was 1.47 (1.04$2.09)$ for overall cancer mortality and 1.43 (1.00-2.04) for nonliver cancer mortality. Furthermore, we confirmed the significant associations between history of transfusion and risk for cancer mortality in subjects with no history of smoking and/or drinking; the HR (95\% CI) was 2.04 (1.39$3.00)$ for overall cancer mortality and 2.01 (1.35-3.00) for nonliver cancer mortality.

Based on the site-specific analysis, we found a significant association between transfusion history and mortality due to cancer in the stomach, liver, and pancreas. After excluding deaths in the first 5 years, there remained significant associations for cancer in liver ( $\mathrm{HR}=1.75,95 \%$ CI: $1.32-2.33)$ and pancreas $(3.20,1.02-10.07)$.

\section{Discussion}

We found that history of blood transfusion before 1990 was mildly but significantly associated with elevated cancer mortality risk among middle-aged and elderly general 
Table 2 Age-adjusted analysis for factors associated with cancer mortality: all cancers, nonliver cancers, and liver cancers

\begin{tabular}{|c|c|c|c|c|c|c|c|c|}
\hline & \multicolumn{3}{|c|}{ Men } & \multicolumn{3}{|c|}{ Women } & \multicolumn{2}{|l|}{ All } \\
\hline & $n$ & HR $(95 \%$ CI $)$ & $P$ value & $n$ & $\mathrm{HR}(95 \% \mathrm{CI})$ & $P$ value & HR $(95 \%$ CI $)$ & $P$ value \\
\hline \multicolumn{9}{|l|}{ Cancer (all) } \\
\hline \multicolumn{9}{|c|}{ Smoking status } \\
\hline Never & 61 & 1.00 & & 147 & 1.00 & & 1.00 & \\
\hline Smoker & 194 & $2.01(1.51-2.69)$ & $<0.0001$ & 8 & $1.75(0.86-3.57)$ & 0.12 & $1.97(1.51-2.57)$ & $<0.0001$ \\
\hline Ex-smoker & 71 & $1.43(1.09-1.89)$ & 0.0107 & 2 & $1.61(0.33-7.74)$ & 0.55 & $1.44(1.10-1.89)$ & 0.0089 \\
\hline \multicolumn{9}{|c|}{ Alcohol intake } \\
\hline Never & 59 & 1.00 & & 124 & 1.00 & & 1.00 & \\
\hline Drinker & 243 & $0.77(0.52-1.13)$ & 0.18 & 49 & $0.60(0.28-1.26)$ & 0.18 & $0.74(0.53-1.05)$ & 0.0888 \\
\hline Ex-drinker & 29 & $1.16(0.75-1.82)$ & 0.51 & 8 & $2.23(1.09-4.56)$ & 0.0279 & $1.36(0.92-2.02)$ & 0.12 \\
\hline \multicolumn{9}{|c|}{ History of external injury } \\
\hline No & 256 & 1.00 & & 140 & 1.00 & & 1.00 & \\
\hline Yes & 72 & $0.87(0.67-1.13)$ & 0.3 & 49 & $1.42(1.02-1.96)$ & 0.0369 & $1.04(0.85-1.27)$ & 0.72 \\
\hline \multicolumn{9}{|c|}{ History of abdominal surgery } \\
\hline No & 250 & 1.00 & & 113 & 1.00 & & 1.00 & \\
\hline Yes & 90 & $1.08(0.85-1.37)$ & 0.55 & 82 & $1.09(0.82-1.45)$ & 0.55 & $1.08(0.90-1.30)$ & 0.41 \\
\hline \multicolumn{9}{|c|}{ History of liver disease } \\
\hline No & 308 & 1.00 & & 177 & 1.00 & & 1.00 & \\
\hline Yes & 17 & $1.28(0.79-2.09)$ & 0.32 & 8 & $1.47(0.72-2.99)$ & 0.29 & $1.34(0.89-2.00)$ & 0.16 \\
\hline \multicolumn{9}{|c|}{ History of blood transfusion } \\
\hline No & 296 & 1.00 & & 153 & 1.00 & & 1.00 & \\
\hline Yes & 37 & $1.33(0.94-1.87)$ & 0.11 & 34 & $1.91(1.32-2.77)$ & 0.0007 & $1.55(1.20-1.99)$ & 0.0006 \\
\hline \multicolumn{9}{|c|}{ History of pregnancy } \\
\hline No & & & & 5 & 1.00 & & & \\
\hline Yes & & & & 169 & $0.42(0.17-1.02)$ & 0.0562 & & \\
\hline \multicolumn{9}{|c|}{ Cancer (nonliver) } \\
\hline \multicolumn{9}{|c|}{ Smoking status } \\
\hline Never & 58 & 1.00 & & 137 & 1.00 & & 1.00 & \\
\hline Smoker & 185 & $2.02(1.50-2.71)$ & $<0.0001$ & 8 & $1.88(0.92-3.84)$ & 0.0827 & $2.00(1.52-2.62)$ & $<0.0001$ \\
\hline Ex-smoker & 68 & $1.44(1.08-1.91)$ & 0.0116 & 2 & $1.61(0.33-7.74)$ & 0.55 & $1.44(1.09-1.90)$ & 0.0096 \\
\hline \multicolumn{9}{|c|}{ Alcohol intake } \\
\hline Never & 58 & 1.00 & & 116 & 1.00 & & 1.00 & \\
\hline Drinker & 233 & $0.86(0.56-1.30)$ & 0.46 & 48 & $0.67(0.30-1.48)$ & 0.32 & $0.83(0.57-1.20)$ & 0.31 \\
\hline Ex-drinker & 25 & $1.02(0.64-1.63)$ & 0.95 & 7 & $2.09(0.98-4.49)$ & 0.0575 & $1.21(0.80-1.82)$ & 0.37 \\
\hline \multicolumn{9}{|c|}{ History of external injury } \\
\hline No & 249 & 1.00 & & 133 & 1.00 & & 1.00 & \\
\hline Yes & 64 & $0.80(0.60-1.05)$ & 0.1 & 45 & $1.37(0.97-1.92)$ & 0.0711 & $0.97(0.78-1.20)$ & 0.77 \\
\hline \multicolumn{9}{|c|}{ History of abdominal surgery } \\
\hline No & 239 & 1.00 & & 108 & 1.00 & & 1.00 & \\
\hline Yes & 86 & $1.08(0.84-1.38)$ & 0.56 & 74 & $1.03(0.77-1.39)$ & 0.85 & $1.06(0.87-1.28)$ & 0.57 \\
\hline \multicolumn{9}{|c|}{ History of liver disease } \\
\hline No & 297 & 1.00 & & 168 & 1.00 & & 1.00 & \\
\hline Yes & 13 & $1.02(0.58-1.77)$ & 0.96 & 6 & $1.16(0.52-2.63)$ & 0.72 & $1.06(0.67-1.68)$ & 0.81 \\
\hline \multicolumn{9}{|c|}{ History of blood transfusion } \\
\hline No & 286 & 1.00 & & 144 & 1.00 & & 1.00 & \\
\hline Yes & 32 & $1.19(0.82-1.71)$ & 0.36 & 32 & $1.91(1.30-2.80)$ & 0.0009 & $1.46(1.12-1.90)$ & 0.005 \\
\hline
\end{tabular}


Table 2 continued

\begin{tabular}{|c|c|c|c|c|c|c|c|c|}
\hline & \multicolumn{3}{|c|}{ Men } & \multicolumn{3}{|c|}{ Women } & \multicolumn{2}{|l|}{ All } \\
\hline & $n$ & $\mathrm{HR}(95 \% \mathrm{CI})$ & $P$ value & $n$ & $\mathrm{HR}(95 \% \mathrm{CI})$ & $P$ value & HR $(95 \% \mathrm{CI})$ & $P$ value \\
\hline \multicolumn{9}{|c|}{ History of pregnancy } \\
\hline No & & & & 4 & 1.00 & & & \\
\hline Yes & & & & 159 & $0.49(0.18-1.33)$ & 0.1615 & & \\
\hline \multicolumn{9}{|c|}{ Cancer (liver) } \\
\hline \multicolumn{9}{|c|}{ History of liver disease } \\
\hline No & 11 & 1.00 & & 9 & 1.00 & & 1.00 & \\
\hline Yes & 4 & $8.27(2.63-26.05)$ & 0.0003 & 2 & $7.21(1.55-33.51)$ & 0.0117 & $7.93(3.18-19.81)$ & $<0.0001$ \\
\hline \multicolumn{9}{|c|}{ History of blood transfusion } \\
\hline No & 10 & 1.00 & & 9 & 1.00 & & 1.00 & \\
\hline Yes & 5 & $5.41(1.84-15.88)$ & 0.0021 & 2 & $1.88(0.41-8.70)$ & 0.42 & $3.56(1.49-8.50)$ & 0.0042 \\
\hline
\end{tabular}

People with history of cancer before participation in the cohort were excluded from this analysis

$H R$ hazard ratio, $C I$ confidence interval

population in Japan who had no history of cancer. These significant associations were maintained even after excluding deaths in the first 5 years, and in subjects who reported no history of smoking and/or drinking.

Site-specific analysis showed a significant association between transfusion history and death from pancreatic cancer. Pancreatic cancer has an extremely low survival rate [16] and is the fifth leading cause of cancer death in Japan [17]. Its incidence and mortality have increased markedly over the past four decades in Japan [18]. Nevertheless, few epidemiological studies have been conducted to identify the environmental/genetic risk factors that contribute to the development of pancreatic cancer, and its etiology remains unclear. Consistent evidence of an association with pancreatic cancer mortality has so far been limited to cigarette smoking [19]. The association between transfusion history and pancreatic cancer in this study needs to be assessed in future studies containing a larger number of cases.

Although this investigation had some limitations, as described below, two main possibilities should be considered if we assume that transfusion history per se leads to an increase in cancer mortality. First, the oncogenic potential of infectious agents transmitted by transfusion is possible. For example, transfusion-transmitted hepatitis virus infection may carry an increased risk for developing a wide range of tumors [20, 21]. Second, the white blood cells and platelets in allogeneic blood transfusion have been suggested to cause transfusion-related immunomodulation (TRIM) [22, 23]. In Japan, until 1988, blood transfusion was performed without filtration or irradiation of white blood cells, or screening for bacterial or viral infections. Whole blood or packed red blood cells were used after matching the allogeneic antigens [24].
In terms of the oncogenic potential of infectious agents, previous studies have suggested that hepatitis $\mathrm{C}$ virus (HCV) might have an oncogenic role in a wide range of cancers [21]. Therefore, an association between history of liver disease and cancer mortality might be an important indicator of whether infectious agents are responsible for the significant association between transfusion history and cancer mortality, because blood transfusion is an important transmission route for HCV in Japan [25, 26]. We found that history of liver disease was associated with history of transfusion, and was significantly associated with increased risk for liver cancer mortality. On the other hand, overall cancer and nonliver cancer mortality were not significantly associated with history of liver disease, but were associated with history of transfusion. This suggests that the increased risk for overall cancer mortality was associated with phenomena induced by pathogens other than infectious agents, which occurs in liver disease.

In terms of the second possibility, TRIM might be directly or indirectly associated with the incidence or promotion of fatal cancer. Clinical and experimental results have shown that allogeneic blood transfusion leads to immunomodulation in the recipient [27-29]. There is epidemiological evidence that TRIM facilitates the recurrence of malignancy or the occurrence of postoperative infections [30-32], although an association with fatal cancer occurrence has not been demonstrated. This condition might be similar to the phenomenon that high-dose immunosuppressive regimens, such as cyclosporine, in transplant recipients lead to a higher frequency of cancer mortality [33]. Therefore, further evidence of the immunosuppressive effect of transfusion on cancer mortality is needed in other populations.

The present study has several limitations. We could not determine the incidence of diseases or other events that 
Table 3 Multivariate analyses for the association between history of transfusion or liver disease and cancer mortality: cancer (specific site), all cancer, and nonliver cancer

\begin{tabular}{|c|c|c|c|c|c|c|}
\hline & \multicolumn{3}{|c|}{ History of transfusion } & \multicolumn{3}{|c|}{ History of liver disease } \\
\hline & $n$ & Adjusted HR (95\% CI) & $P$ value & $n$ & Adjusted HR (95\% CI) & $P$ value \\
\hline \multicolumn{7}{|c|}{ Cancer (all) } \\
\hline All & 71 & $1.75(1.32-2.33)$ & 0.0001 & 25 & $1.26(0.83-1.91)$ & 0.27 \\
\hline Men & 37 & $1.47(1.00-2.18)$ & 0.0522 & 17 & $1.26(0.76-2.09)$ & 0.38 \\
\hline Women & 34 & $2.18(1.39-3.43)$ & 0.0007 & 8 & $1.39(0.67-2.84)$ & 0.37 \\
\hline \multicolumn{7}{|c|}{ Cancer (nonliver) } \\
\hline All & 64 & $1.68(1.25-2.26)$ & 0.0007 & 19 & $1.00(0.62-1.61)$ & 0.99 \\
\hline Men & 32 & $1.33(0.87-2.02)$ & 0.18 & 13 & $1.01(0.56-1.81)$ & 0.98 \\
\hline Women & 32 & $2.20(1.38-3.51)$ & 0.0009 & 6 & $1.08(0.47-2.45)$ & 0.86 \\
\hline \multicolumn{7}{|c|}{ Cancer (specific site) } \\
\hline \multicolumn{7}{|l|}{ Lung } \\
\hline All & 12 & $1.54(0.78-3.06)$ & 0.22 & 4 & $1.06(0.39-2.91)$ & 0.91 \\
\hline Men & 7 & $1.12(0.46-2.75)$ & 0.8 & 3 & $1.09(0.34-3.50)$ & 0.88 \\
\hline Women & 5 & $2.87(0.90-9.14)$ & 0.07 & 1 & $1.31(0.17-10.18)$ & 0.79 \\
\hline \multicolumn{7}{|l|}{ Stomach } \\
\hline All & 13 & $1.99(1.01-3.91)$ & 0.0462 & 4 & $1.17(0.42-3.23)$ & 0.76 \\
\hline Men & 7 & $1.35(0.55-3.34)$ & 0.51 & 3 & $0.78(0.19-3.22)$ & 0.73 \\
\hline Women & 6 & $3.24(0.91-11.52)$ & 0.0698 & 1 & $2.32(0.53-10.11)$ & 0.26 \\
\hline \multicolumn{7}{|c|}{ Colorectum } \\
\hline All & 6 & $1.27(0.46-3.46)$ & 0.65 & 1 & $0.68(0.09-5.02)$ & 0.71 \\
\hline Men & 1 & $\mathrm{n} / \mathrm{a}$ & $\mathrm{n} / \mathrm{a}$ & 1 & $2.40(0.31-18.60)$ & 0.4 \\
\hline Women & 5 & $1.25(0.34-4.59)$ & 0.7334 & 0 & $\mathrm{n} / \mathrm{a}$ & $\mathrm{n} / \mathrm{a}$ \\
\hline \multicolumn{7}{|l|}{ Liver } \\
\hline All & 7 & $3.07(1.14-8.31)$ & 0.0269 & 6 & $6.57(2.51-17.23)$ & 0.0001 \\
\hline Men & 5 & $3.94(1.19-13.08)$ & 0.025 & 4 & $5.45(1.65-17.93)$ & 0.0053 \\
\hline Women & 2 & $2.15(0.35-11.89)$ & 0.4259 & 2 & $9.04(1.80-45.40)$ & 0.0075 \\
\hline \multicolumn{7}{|l|}{ Pancreas } \\
\hline All & 7 & $3.34(1.28-8.72)$ & 0.014 & 0 & $\mathrm{n} / \mathrm{a}$ & $\mathrm{n} / \mathrm{a}$ \\
\hline Men & 4 & $4.10(1.12-14.98)$ & 0.0328 & 0 & $\mathrm{n} / \mathrm{a}$ & $\mathrm{n} / \mathrm{a}$ \\
\hline Women & 3 & $2.57(0.63-10.60)$ & 0.1905 & 0 & $\mathrm{n} / \mathrm{a}$ & $\mathrm{n} / \mathrm{a}$ \\
\hline \multicolumn{7}{|l|}{ Other } \\
\hline All & 26 & $1.47(0.89-2.42)$ & 0.13 & 9 & $1.26(0.61-2.59)$ & 0.53 \\
\hline Men & 13 & $1.32(0.67-2.57)$ & 0.42 & 6 & $1.12(0.45-2.77)$ & 0.81 \\
\hline Women & 13 & $1.70(0.80-3.61)$ & 0.16 & 3 & $1.58(0.49-5.13)$ & 0.45 \\
\hline
\end{tabular}

Adjusted HR for cancer mortality was estimated after adjustment for age, sex, and typical risk factors for overall cancer mortality [smoking status (never smokers, current smokers or ex-smokers) and alcohol consumption (never drinkers, current drinkers or ex-drinkers)], history of pregnancy (yes or no), and other factors that may have been related to transfusion or that showed a significant association in the age-adjusted univariate analysis (history of external injury, abdominal surgery, and liver disease). People with history of cancer before participation in the cohort were excluded from this analysis. Each specific site of cancer was defined from ICD, tenth revision, as lung (C34), stomach (C16), colorectum (C18), liver (C22), pancreas (C25)

$n / a$ not applicable

might have been related to cancer mortality following entry to the study, and therefore it is possible that unrecognized confounding factors might be related to the association between history of transfusion and cancer mortality.

Another limitation is that this survey collected selfreported transfusion history, which may have reduced the objectivity of the study. It is also possible that some cancer deaths were not recorded in the cohort, specifically those who left their original communities to undergo long-term hospitalization. These factors may have hindered accurate calculation of the association between transfusion history and cancer mortality. On the other hand, we could not use background information on the transfusion procedure. Therefore, the possibility of biased selection of persons 
receiving blood transfusions cannot be ignored. Finally, because this study contained relatively small numbers of cancer mortality for each site, it is possible that statistical errors may have had an adverse influence on the results.

In this study, we found that history of blood transfusion prior to 1990 in middle-aged and elderly general population in Japan was mildly but significantly associated with cancer mortality, in terms of overall cancer and nonliver cancer. The strength of our study was that we tested and confirmed the association between transfusion history and overall or site-specific cancer mortality, by conducting a long-term follow-up cohort study. In addition, the significant association remained even after adjusting for known major cancer mortality factors such as alcohol intake and smoking, and after excluding early deaths, which might have been related to unidentified factors that may engender a spurious association between transfusion history and cancer mortality, and our results showed that this association seemed to be independent from the oncogenic action induced by infectious agents from transfusion. Since 1990, the system and procedures used for transfusion in Japan have evolved dramatically; therefore, we need to evaluate whether current regimens have reduced the risk for major disease such as cancer.

Acknowledgments The authors wish to thank the staff of the health check-up programs and the residents of the four areas in Akita Prefecture for their support of our research. The JACC study was supported by Grants-in-Aid for Scientific Research from the Ministry of Education, Science, Sports, and Culture of Japan (nos. 61010076, 62010074, 63010074, 1010068, 2151065, 3151064, 4151063, 5151069, 6279102, and 11181101).

\section{References}

1. Tartter PI. Blood transfusion history in colorectal cancer patients and cancer-free controls. Transfusion. 1988;28:593-6.

2. Woolley AL, Hogikyan ND, Gates GA, Haughey BH, Schechtman KB, Goldenberg JL. Effect of blood transfusion on recurrence of head and neck carcinoma. Retrospective review and meta-analysis. Ann Otol Rhinol Laryngol. 1992;101:724-30.

3. Bordin JO, Heddle NM, Blajchman MA. Biologic effects of leukocytes present in transfused cellular blood products. Blood. 1994;84:1703-21.

4. Blajchman MA, Bordin JO. Mechanisms of transfusion-associated immunosuppression. Curr Opin Hematol. 1994;1:457-61.

5. Vamvakas EC. Perioperative blood transfusion and cancer recurrence: meta-analysis for explanation. Transfusion. 1995;35:760-8.

6. Vamvakas EC. Transfusion-associated cancer recurrence and postoperative infection: meta analysis of randomized, controlled clinical trials. Transfusion. 1996;36:175-86.

7. Landers DF, Hill GE, Wong KC, Fox IJ. Blood transfusioninduced immunomodulation. Anesth Analg. 1996;82:187-204.

8. Blumberg N, Heal JM. Immunological tolerance. Science. 1996;272:1408.

9. Blumberg N, Heal JM. Immunomodulation by blood transfusion: an evolving scientific and clinical challenge. Am J Med. 1996;101:299-308.
10. Klein HG. Immunomodulatory aspects of transfusion: a once and future risk? Anesthesiology. 1999;91:861-5.

11. Brand A. Immunological aspects of blood transfusions. Blood Rev. 2000;14:130-44.

12. Vamvakas EC. WBC-containing allogeneic blood transfusion and mortality: a meta-analysis of randomized controlled trials. Transfusion. 2003;43:963-73.

13. Kikuchi S. Japan Collaborative Cohort Study for Evaluation of Cancer. Personal past history and mortality in the Japan Collaborative Cohort Study for Evaluation of Cancer (JACC). Asian Pac J Cancer Prev. 2007;8(Suppl):9-20.

14. Ohno Y, Tamakoshi A, for the JACC Study Group. Japan collaborative cohort study for evaluation of cancer risk sponsored by Monbusho (JACC Study). J Epidemiol. 2001;11:144-50.

15. Tamakoshi A, Yoshimura $\mathrm{Y}$, Inaba $\mathrm{Y}$, Ito $\mathrm{Y}$, Watanabe $\mathrm{Y}$, Fukuda K, et al. Profile of the JACC Study. J Epidemiol. 2005;15:S4-8.

16. American Cancer Society. Cancer facts and figures 2005. Atlanta: American Cancer Society; 2005.

17. Ministry of Health, Labour and Welfare of Japan. Annual Reports of The National Vital Statistics, 1997, 1998, 1999, 2000, 2001, 2002, 2003, 2004, 2005. Tokyo: 1998, 1999, 2000, 2001, 2002, 2003, 2004, 2005 and 2006 (in Japanese).

18. Lin Y, Tamakoshi A, Wakai K, Kawamura T, Aoki R, Kojima M, et al. Descriptive epidemiology of pancreatic cancer in Japan. J Epidemiol. 1998;8:52-9.

19. International Agency for Research on Cancer (IARC). Monographs on the evaluation of carcinogenic risks to humans, vol 83. Tobacco smoke and involuntary smoking. Lyon: IARC; 2004.

20. Sene D, Limal N, Cacoub P. Hepatitis C virus-associated extrahepatic manifestations: a review. Metab Brain Dis. 2004;19:3-4.

21. Malaguarnera M, Gargante MP, Risino C, Ranno S, Berretta M, Cannizzaro MA, et al. Hepatitis $\mathrm{C}$ virus in elderly cancer patients. Eur J Intern Med. 2006;17:325-9.

22. Merryman HT. Transfusion-induced alloimmunization and immunosuppression and the effects of leukocyte depletion. Transfus Med. 1989;3:180-93.

23. Aslam R, Speck ER, Kim M, Freedman J, Semple JW. Transfusion-related immunomodulation by platelets is dependent on their expression of MHC class I molecules and is independent of white cells. Transfusion. 2008;48:1778-86.

24. Japanese Red Cross Non-A Non-B Hepatitis Research Group. Effect of screening for hepatitis $\mathrm{C}$ virus antibody and hepatitis $\mathrm{B}$ virus core antibody on incidence of post-transfusion hepatitis. Lancet. 1991;338:1040-1.

25. Fujino Y, Tamakoshi A, Hoshiyama Y, Mikami H, Okamoto N, Ohno Y, et al. Prospective study of transfusion history and thyroid cancer incidence among females in Japan. Int $\mathrm{J}$ Cancer. 2004; $112: 722-5$.

26. Kiyosawa K, Umemura T, Ichijo T, Matsumoto A, Yoshizawa K, $\mathrm{Gad} \mathrm{A}$, et al. Hepatocellular carcinoma: recent trends carcinoma: recent trends in Japan. Gastroenterology. 2004;127:S17-26.

27. Hill GE, Frawley WH, Griffith KE, Forestner JE, Minei JP. Allogeneic blood transfusion increases the risk of postoperative bacterial infection: a meta-analysis. J Trauma. 2003;54:908-14.

28. Shorr AF, Jackson WL. Transfusion practice and nosocomial infection: assessing the evidence. Curr Opin Crit Care. 2005;11:468-72.

29. Siemionow M, Agaoglu G. Role of blood transfusion in transplantation: a review. J Reconstr Microsurg. 2005;21:555-63.

30. Heiss MM, Mempel W, Jauch KW, Delanoff C, Mayer G, Mempel M, et al. Beneficial effect of autologous blood transfusion on infectious complications after colorectal cancer surgery. Lancet. 1993;342:1328-33.

31. van de Watering LM, Hermans J, Houbiers JG, van den Broek PJ, Bouter H, Boer F, et al. Beneficial effects of leukocyte depletion 
of transfused blood on postoperative complications in patients undergoing cardiac surgery: a randomized clinical trial. Circulation. 1998;97:562-8.

32. Bilgin YM, van de Watering LM, Eijsman L, Versteegh MI, Brand $\mathrm{R}$, van Oers $\mathrm{MH}$, et al. Double-blind, randomized controlled trial on the effect of leukocyte-depleted erythrocyte transfusions in cardiac valve surgery. Circulation. 2004;109: 2755-60.

33. Dantal J, Hourmant M, Cantarovich D, Giral M, Blancho G, Dreno B, et al. Effect of long-term immunosuppression in kidneygraft recipients on cancer incidence: randomised comparison of two cyclosporin regimens. Lancet. 1998;351:623-8. 